\title{
Some Results on Strictly Pseudocontractive Nonself-Mappings and Equilibrium Problems in Hilbert Spaces
}

\author{
Yan $\mathrm{Hao}^{1}$ and Sun Young $\mathrm{Cho}^{2}$ \\ ${ }^{1}$ School of Mathematics Physics and Information Science, Zhejiang Ocean University, \\ Zhoushan 316004, China \\ ${ }^{2}$ Department of Mathematics, Gyeongsang National University, \\ Jinju 660-701, Republic of Korea
}

Correspondence should be addressed to Yan Hao, zjhaoyan@yahoo.cn

Received 12 September 2012; Accepted 6 October 2012

Academic Editor: Yonghong Yao

Copyright (C) 2012 Y. Hao and S. Y. Cho. This is an open access article distributed under the Creative Commons Attribution License, which permits unrestricted use, distribution, and reproduction in any medium, provided the original work is properly cited.

An equilibrium problem and a strictly pseudocontractive nonself-mapping are investigated. Strong convergence theorems of common elements are established based on hybrid projection algorithms in the framework of real Hilbert spaces.

\section{Introduction}

Bifunction equilibrium problems which were considered by Blum and Oettli [1] have intensively been studied. It has been shown that the bifunction equilibrium problem covers fixed point problems, variational inequalities, inclusion problems, saddle problems, complementarity problem, minimization problem, and the Nash equilibrium problem; see [1-4] and the references therein. Iterative methods have emerged as an effective and powerful tool for studying a wide class of problems which arise in economics, finance, image reconstruction, ecology, transportation, network, elasticity, and optimization; see [516] and the references therein. In this paper, we investigate an equilibrium problem and a strictly pseudocontractive nonself-mapping based on hybrid projection algorithms. Strong convergence theorems of common elements lie in the solution set of the equilibrium problem and the fixed point set of the strictly pseudocontractive nonself-mapping.

Throughout this paper, we always assume that $H$ is a real Hilbert space with the inner product $\langle\cdot, \cdot\rangle$ and the norm $\|\cdot\|$. Let $C$ be a nonempty closed convex subset of $H$ and $F$ a 
bifunction of $C \times C$ into $\mathbb{R}$, where $\mathbb{R}$ denotes the set of real numbers. In this paper, we consider the following equilibrium problem:

$$
\text { Find } x \in C \text { such that } F(x, y) \geq 0, \quad \forall y \in C \text {. }
$$

The set of such an $x \in C$ is denoted by $E P(F)$, that is,

$$
E P(F)=\{x \in C: F(x, y) \geq 0, \forall y \in C\}
$$

Given a mapping $T: C \rightarrow H$, let $F(x, y)=\langle T x, y-x\rangle$ for all $x, y \in C$. Then $z \in E P(F)$ if and only if $\langle T z, y-z\rangle \geq 0$ for all $y \in C$, that is, $z$ is a solution of the variational inequality. conditions:

To study the equilibrium problem (1.1), we may assume that $F$ satisfies the following

(A1) $F(x, x)=0$ for all $x \in C$;

(A2) $F$ is monotone, that is, $F(x, y)+F(y, x) \leq 0$ for all $x, y \in C$;

(A3) for each $x, y, z \in C$,

$$
\limsup _{t \downarrow 0} F(t z+(1-t) x, y) \leq F(x, y)
$$

(A4) for each $x \in C, y \mapsto F(x, y)$ is convex and lower semicontinuous.

If $H$ is an Euclidean space, then we see that $F(x, y)=x-y$ is a simple example satisfying the above assumptions. See [2] for more details. Let $S: D(S) \rightarrow R(S)$, where $D(S)$ and $R(S)$ denote the domain and the range of the mapping $S$. If $D(S)=R(S)$, then the mapping $S$ is said to be a self-mapping. If $D(S) \neq R(S)$, then the mapping $S$ is said to be a nonself-mapping. Let $S: C \rightarrow H$ be a nonself-mapping. In this paper, we use $F(S)$ to denote the fixed point set of $S$. Recall the following definitions. $S$ is said to be nonexpansive if

$$
\|S x-S y\| \leq\|x-y\|, \quad \forall x, y \in C
$$

$S$ is said to be strictly pseudocontractive if there exists a constant $\kappa \in[0,1)$ such that

$$
\|S x-S y\|^{2} \leq\|x-y\|^{2}+\kappa\|(I-S) x-(I-S) y\|^{2}, \quad \forall x, y \in C
$$

For such a case, $S$ is also said to be $\mathcal{\kappa}$-strict pseudocontraction. It is clear that (1.5) is equivalent to

$$
\langle S x-S y, x-y\rangle \leq\|x-y\|^{2}-\frac{1-\kappa}{2}\|(x-S x)-(y-S y)\|^{2}, \quad \forall x, y \in C .
$$

$S$ is said to be pseudocontractive if

$$
\|S x-S y\|^{2} \leq\|x-y\|^{2}+\|(I-S) x-(I-S) y\|^{2}, \quad \forall x, y \in C .
$$


It is clear that (1.7) is equivalent to

$$
\langle S x-S y, x-y\rangle \leq\|x-y\|^{2}, \quad \forall x, y \in C .
$$

The class of $\kappa$-strict pseudocontractions which was introduced by Browder and Petryshyn [17] in 1967 has been considered by many authors. It is easy to see that the class of strict pseudocontractions falls into the one between the class of nonexpansive mappings and the class of pseudocontractions. For studying the class of strict pseudocontractions, Zhou [18] proposed the following convex combination method: define a mapping $S_{t}: \mathrm{C} \rightarrow \mathrm{H}$ by

$$
S_{t} x=t x+(1-t) S x, \quad \forall x \in C .
$$

He showed that $S_{t}$ is nonexpansive if $t \in[\kappa, 1)$; see [18] for more details.

Recently, many authors considered the problem of finding a common element in the fixed point set of a nonexpansive mapping and in the solution set of the equilibrium problem (1.1) based on iterative methods; see, for instance, [19-27].

In 2007, Tada and Takahashi [23] considered an iterative method for the equilibrium problem (1.1) and a nonexpansive nonself-mapping. To be more precise, they obtained the following results.

Theorem TT. Let $C$ be a closed convex subset of a real Hilbert space $H$, let $f: C \times C \rightarrow \mathbb{R}$ be a bifunction satisfying (A1)-(A4), and let $S$ be a nonexpansive mapping of $C$ into $H$ such that $F(S) \cap E P(f) \neq \emptyset$. Let $\left\{x_{n}\right\}$ and $\left\{u_{n}\right\}$ be sequences generated by $x_{1}=x \in H$, and let

$$
\begin{gathered}
u_{n} \in C \text { such that } f\left(u_{n}, y\right)+\frac{1}{r_{n}}\left\langle y-u_{n}, u_{n}-x_{n}\right\rangle \geq 0, \quad \forall y \in C, \\
w_{n}=\left(1-\alpha_{n}\right) x_{n}+\alpha_{n} S u_{n}, \\
C_{n}=\left\{z \in H:\left\|w_{n}-z\right\| \leq\left\|x_{n}-z\right\|\right\}, \\
Q_{n}=\left\{z \in H:\left\langle x_{n}-z, x-x_{n}\right\rangle \geq 0\right\}, \\
x_{n+1}=P_{C_{n} \cap Q_{n}} x,
\end{gathered}
$$

for every $n \in \mathbb{N}$, where $\left\{\alpha_{n}\right\} \subset[a, 1]$, for some $a \in(0,1)$ and $\left\{r_{n}\right\} \subset(0, \infty)$ satisfies $\liminf _{n \rightarrow \infty} r_{n}>$ 0 . Then the sequence $\left\{x_{n}\right\}$ converges strongly to $P_{F(S) \cap E P(f)}(x)$.

We remark that the iterative process (1.10) is called the hybrid projection iterative process. Recently, the hybrid projection iterative process which was first considered by Haugazeau [28] in 1968 has been studied for fixed point problem of nonlinear mappings and equilibrium problems by many authors. Since the sequence generated in the hybrid projection iterative process depends on the sets $C_{n}$ and $Q_{n}$, the hybrid projection iterative process is also known as "CQ" iterative process; see [29] and the reference therein.

Recently, Takahashi et al. [30] considered the shrinking projection process for the fixed point problem of nonexpansive self-mapping. More precisely, they obtain the iterative sequence monontonely without the help of the set $Q_{n}$; see [30] for more details.

In this paper, we reconsider the same shrinking projection process for the equilibrium problem (1.1) and a strictly pseudocontractive nonself-mapping. We show that the sequence 
generated in the proposed iterative process converges strongly to some common element in the fixed point set of a strictly pseudocontractive nonself-mapping and in the solution set of the equilibrium problem (1.1). The main results presented in this paper mainly improved the corresponding results in Tada and Takahashi [23].

\section{Preliminaries}

Let $C$ be a nonempty closed and convex subset of a real Hilbert space $H$. Let $P_{C}$ be the metric projection from $H$ onto $C$. That is, for $x \in H, P_{C} x$ is the only point in $C$ such that $\left\|x-P_{C} x\right\|=$ $\inf \{\|x-z\|: z \in C\}$. We know that the mapping $P_{C}$ is firmly nonexpansive, that is,

$$
\left\|P_{C} x-P_{C} y\right\|^{2} \leq\left\langle P_{C} x-P_{C} y, x-y\right\rangle, \quad \forall x, y \in H
$$

The following lemma can be found in [1,2].

Lemma 2.1. Let $C$ be a nonempty closed convex subset of $H$, and let $F: C \times C \rightarrow \mathbb{R}$ be a bifunction satisfying (A1)-(A4). Then, for any $r>0$ and $x \in H$, there exists $z \in C$ such that

$$
F(z, y)+\frac{1}{r}\langle y-z, z-x\rangle \geq 0, \quad \forall y \in C
$$

Further, define

$$
T_{r} x=\left\{z \in C: F(z, y)+\frac{1}{r}\langle y-z, z-x\rangle \geq 0, \forall y \in C\right\}
$$

for all $r>0$ and $x \in H$. Then, the following hold:

(a) $T_{r}$ is single valued;

(b) $T_{r}$ is firmly nonexpansive, that is,

$$
\left\|T_{r} x-T_{r} y\right\|^{2} \leq\left\langle T_{r} x-T_{r} y, x-y\right\rangle, \quad \forall x, y \in H ;
$$

(c) $F\left(T_{r}\right)=E P(F)$;

(d) $E P(F)$ is closed and convex.

Lemma 2.2 (see [18]). Let $H$ be a real Hilbert space, $C$ a nonempty closed convex subset of $H$, and $S: C \rightarrow H$ a strict pseudocontraction. Then the mapping $I-S$ is demiclosed at zero, that is, if $\left\{x_{n}\right\}$ is a sequence in $C$ such that $x_{n} \rightarrow \bar{x}$ and $x_{n}-S x_{n} \rightarrow 0$, then $\bar{x} \in F(S)$.

Lemma 2.3 (see [18]). Let $C$ be a nonempty closed convex subset of a real Hilbert space $H$ and $S: C \rightarrow H$ a -strict pseudocontraction. Define a mapping $S_{\alpha} x=\alpha x+(1-\alpha) S x$ for all $x \in C$. If $\alpha \in[\kappa, 1)$, then the mapping $S_{\alpha}$ is a nonexpansive mapping such that $F\left(S_{\alpha}\right)=F(S)$. 


\section{Main Results}

Theorem 3.1. Let $C$ be a nonempty closed convex subset of a real Hilbert space $H$. Let $F_{1}$ and $F_{2}$ be two bifunctions from $C \times C$ to $\mathbb{R}$ which satisfy $(A 1)-(A 4)$, respectively. Let $S: C \rightarrow H$ be a $\kappa$-strict pseudocontraction. Assume that $\mathcal{F}:=E P\left(F_{1}\right) \cap E P\left(F_{2}\right) \cap F(S) \neq \emptyset$. Let $\left\{\alpha_{n}\right\},\left\{\beta_{n}\right\}$, and $\left\{\gamma_{n}\right\}$ be sequences in $[0,1]$. Let $\left\{x_{n}\right\}$ be a sequence generated in the following manner:

$$
\begin{gathered}
x_{1} \in H, \\
C_{1}=H, \\
z_{n}=\gamma_{n} u_{n}+\left(1-\gamma_{n}\right) v_{n}, \\
y_{n}=\alpha_{n} x_{n}+\left(1-\alpha_{n}\right)\left(\beta_{n} z_{n}+\left(1-\beta_{n}\right) S z_{n}\right), \\
C_{n+1}=\left\{w \in C_{n}:\left\|y_{n}-w\right\| \leq\left\|x_{n}-w\right\|\right\}, \\
x_{n+1}=P_{C_{n+1}} x_{1}, \quad n \geq 0,
\end{gathered}
$$

where $u_{n}$ is chosen such that

$$
F_{1}\left(u_{n}, u\right)+\frac{1}{r_{n}}\left\langle u-u_{n}, u_{n}-x_{n}\right\rangle \geq 0, \quad \forall u \in C,
$$

and $v_{n}$ is chosen such that

$$
F_{2}\left(v_{n}, v\right)+\frac{1}{s_{n}}\left\langle v-v_{n}, v_{n}-x_{n}\right\rangle \geq 0, \quad \forall v \in C
$$

Assume that the control sequences $\left\{\alpha_{n}\right\},\left\{\beta_{n}\right\},\left\{\gamma_{n}\right\},\left\{r_{n}\right\}$, and $\left\{s_{n}\right\}$ satisfy the following restrictions:

(a) $0 \leq \alpha_{n} \leq a<1, \kappa \leq \beta_{n} \leq b<1,0<c \leq \gamma_{n} \leq d<1$;

(b) $0<e \leq r_{n}, 0<f \leq s_{n}$

for some $a, b, c, d, e, f \in \mathbb{R}$. Then the sequence $\left\{x_{n}\right\}$ generated in the $(\Delta)$ converges strongly to some point $\bar{x}$, where $\bar{x}=P_{\mp} x_{1}$.

Proof. First, we show that $C_{n}$ is closed and convex for each $n \geq 1$. It is easy to see that $C_{n}$ is closed for each $n \geq 1$. We only show that $C_{n}$ is convex for each $n \geq 1$. Note that $C_{1}=H$ is convex. Suppose that $C_{m}$ is convex for some positive integer $m$. Next, we show that $C_{m+1}$ is convex for the same $m$. Note that $\left\|y_{n}-w\right\| \leq\left\|x_{n}-w\right\|$ is equivalent to

$$
2\left\langle x_{n}-y_{n}, w\right\rangle \leq\left\|x_{n}\right\|^{2}-\left\|y_{n}\right\|^{2}
$$

Take $w_{1}$ and $w_{2}$ in $C_{m+1}$, and put $\bar{w}=t w_{1}+(1-t) w_{2}$. It follows that $w_{1} \in C_{m}, w_{2} \in C_{m}$

$$
\begin{aligned}
& 2\left\langle x_{n}-y_{n}, w_{1}\right\rangle \leq\left\|x_{n}\right\|^{2}-\left\|y_{n}\right\|^{2}, \\
& 2\left\langle x_{n}-y_{n}, w_{2}\right\rangle \leq\left\|x_{n}\right\|^{2}-\left\|y_{n}\right\|^{2} .
\end{aligned}
$$


Combining (3.4), we can obtain that $2\left\langle x_{n}-y_{n}, \bar{w}\right\rangle \leq\left\|x_{n}\right\|^{2}-\left\|y_{n}\right\|^{2}$, that is, $\left\|y_{n}-\bar{w}\right\| \leq\left\|x_{n}-\bar{w}\right\|$. In view of the convexity of $C_{m}$, we see that $\bar{w} \in C_{m}$. This shows that $\bar{w} \in C_{m+1}$. This concludes that $C_{n}$ is closed and convex for each $n \geq 1$.

Define a mapping $S_{n}: C \rightarrow H$ by $S_{n} x=\beta_{n} x+\left(1-\beta_{n}\right) S x$ for all $x \in C$. It follows from Lemma 2.3 that $S_{n}$ is nonexpansive and $F\left(S_{n}\right)=F(S)$ for all $n \geq 1$. Next, we show that $\mathcal{F} \subset C_{n}$ for all $n \geq 1$. It is easy to see that $\mathcal{F} \subset C_{1}=H$. Suppose that $\mathcal{F} \subset C_{k}$ for some integer $k \geq 1$. We intend to claim that $\mathscr{F} \subset C_{k+1}$ for the same $k$. For any $p \in \mathscr{F} \subset C_{k}$, we have

$$
\begin{aligned}
\left\|y_{k}-p\right\| & \leq \alpha_{k}\left\|x_{k}-p\right\|+\left(1-\alpha_{k}\right)\left\|S_{k} z_{k}-p\right\| \\
& \leq \alpha_{k}\left\|x_{k}-p\right\|+\left(1-\alpha_{k}\right)\left\|z_{k}-p\right\| \\
& \leq \alpha_{k}\left\|x_{k}-p\right\|+\left(1-\alpha_{k}\right)\left(\gamma_{k}\left\|u_{k}-p\right\|+\left(1-\gamma_{k}\right)\left\|v_{k}-p\right\|\right) \\
& =\alpha_{k}\left\|x_{k}-p\right\|+\left(1-\alpha_{k}\right)\left(\gamma_{k}\left\|T_{r_{k}} x_{k}-p\right\|+\left(1-\gamma_{k}\right)\left\|T_{s_{k}} x_{k}-p\right\|\right) \\
& \leq \alpha_{k}\left\|x_{k}-p\right\|+\left(1-\alpha_{k}\right)\left(\gamma_{k}\left\|x_{k}-p\right\|+\left(1-\gamma_{k}\right)\left\|x_{k}-p\right\|\right) \\
& =\left\|x_{k}-p\right\| .
\end{aligned}
$$

This shows that $p \in C_{k+1}$. This proves that $\mathcal{F} \subset C_{n}$ for all $n \geq 1$.

Since $x_{n}=P_{C_{n}} x_{1}$ and $x_{n+1}=P_{C_{n+1}} x_{1} \in C_{n+1} \subset C_{n}$, we have that

$$
\begin{aligned}
0 & \leq\left\langle x_{1}-x_{n}, x_{n}-x_{n+1}\right\rangle \\
& =\left\langle x_{1}-x_{n}, x_{n}-x_{1}+x_{1}-x_{n+1}\right\rangle \\
& \leq-\left\|x_{1}-x_{n}\right\|^{2}+\left\|x_{1}-x_{n}\right\|\left\|x_{1}-x_{n+1}\right\| .
\end{aligned}
$$

It follows that

$$
\left\|x_{1}-x_{n}\right\| \leq\left\|x_{1}-x_{n+1}\right\| .
$$

On the other hand, for any $p \in \mathcal{F} \subset C_{n}$, we see that $\left\|x_{1}-x_{n}\right\| \leq\left\|x_{1}-p\right\|$. In particular, we have

$$
\left\|x_{1}-x_{n}\right\| \leq\left\|x_{1}-P_{\mp} x_{1}\right\| .
$$


This shows that the sequence $\left\{x_{n}\right\}$ is bounded. In view of (3.7), we see that $\lim _{n \rightarrow \infty}\left\|x_{n}-x_{1}\right\|$ exists. It follows from (3.6) that

$$
\begin{aligned}
\| x_{n}- & x_{n+1} \|^{2} \\
& =\left\|x_{n}-x_{1}+x_{1}-x_{n+1}\right\|^{2} \\
& =\left\|x_{n}-x_{1}\right\|^{2}+2\left\langle x_{n}-x_{1}, x_{1}-x_{n+1}\right\rangle+\left\|x_{1}-x_{n+1}\right\|^{2} \\
& =\left\|x_{n}-x_{1}\right\|^{2}+2\left\langle x_{n}-x_{1}, x_{1}-x_{n}+x_{n}-x_{n+1}\right\rangle+\left\|x_{1}-x_{n+1}\right\|^{2} \\
& =\left\|x_{n}-x_{1}\right\|^{2}-2\left\|x_{n}-x_{1}\right\|^{2}+2\left\langle x_{n}-x_{1}, x_{n}-x_{n+1}\right\rangle+\left\|x_{1}-x_{n+1}\right\|^{2} \\
& \leq\left\|x_{1}-x_{n+1}\right\|^{2}-\left\|x_{n}-x_{1}\right\|^{2} .
\end{aligned}
$$

This yields that

$$
\lim _{n \rightarrow \infty}\left\|x_{n}-x_{n+1}\right\|=0
$$

Since $x_{n+1}=P_{C_{n+1}} x_{1} \in C_{n+1}$, we see that

$$
\left\|y_{n}-x_{n+1}\right\| \leq\left\|x_{n}-x_{n+1}\right\|
$$

It follows that

$$
\left\|y_{n}-x_{n}\right\| \leq\left\|y_{n}-x_{n+1}\right\|+\left\|x_{n+1}-x_{n}\right\| \leq 2\left\|x_{n}-x_{n+1}\right\|
$$

From (3.10), we obtain that

$$
\lim _{n \rightarrow \infty}\left\|x_{n}-y_{n}\right\|=0
$$

On the other hand, we have

$$
\left\|x_{n}-y_{n}\right\|=\left\|x_{n}-\alpha_{n} x_{n}-\left(1-\alpha_{n}\right) S_{n} z_{n}\right\|=\left(1-\alpha_{n}\right)\left\|x_{n}-S_{n} z_{n}\right\|
$$

From the restriction (a), we obtain from (3.13) that

$$
\lim _{n \rightarrow \infty}\left\|x_{n}-S_{n} z_{n}\right\|=0
$$


For any $p \in \mathcal{F}$, we have that

$$
\begin{aligned}
\left\|u_{n}-p\right\|^{2} & =\left\|T_{r_{n}} x_{n}-T_{r_{n}} p\right\|^{2} \\
& \leq\left\langle T_{r_{n}} x_{n}-T_{r_{n}} p, x_{n}-p\right\rangle \\
& =\left\langle u_{n}-p, x_{n}-p\right\rangle \\
& =\frac{1}{2}\left(\left\|u_{n}-p\right\|^{2}+\left\|x_{n}-p\right\|^{2}-\left\|u_{n}-x_{n}\right\|^{2}\right) .
\end{aligned}
$$

This implies that

$$
\left\|u_{n}-p\right\|^{2} \leq\left\|x_{n}-p\right\|^{2}-\left\|u_{n}-x_{n}\right\|^{2} .
$$

In a similar way, we get that

$$
\left\|v_{n}-p\right\|^{2} \leq\left\|x_{n}-p\right\|^{2}-\left\|v_{n}-x_{n}\right\|^{2} .
$$

It follows from (3.17) and (3.18) that

$$
\begin{aligned}
\left\|y_{n}-p\right\|^{2} & \leq \alpha_{n}\left\|x_{n}-p\right\|^{2}+\left(1-\alpha_{n}\right)\left\|S_{n} z_{n}-p\right\|^{2} \\
& \leq \alpha_{n}\left\|x_{n}-p\right\|^{2}+\left(1-\alpha_{n}\right)\left\|z_{n}-p\right\|^{2} \\
& \leq \alpha_{n}\left\|x_{n}-p\right\|^{2}+\left(1-\alpha_{n}\right)\left(\gamma_{n}\left\|u_{n}-p\right\|^{2}+\left(1-\gamma_{n}\right)\left\|v_{n}-p\right\|^{2}\right) \\
& \leq\left\|x_{n}-p\right\|^{2}-\left(1-\alpha_{n}\right) \gamma_{n}\left\|u_{n}-x_{n}\right\|^{2}-\left(1-\alpha_{n}\right)\left(1-\gamma_{n}\right)\left\|v_{n}-x_{n}\right\|^{2} .
\end{aligned}
$$

This implies that

$$
\begin{aligned}
\left(1-\alpha_{n}\right) \gamma_{n}\left\|u_{n}-x_{n}\right\|^{2} & \leq\left\|x_{n}-p\right\|^{2}-\left\|y_{n}-p\right\|^{2} \\
& \leq\left(\left\|x_{n}-p\right\|+\left\|y_{n}-p\right\|\right)\left\|x_{n}-y_{n}\right\| .
\end{aligned}
$$

In view of the restriction (a), we obtain from (3.13) that

$$
\lim _{n \rightarrow \infty}\left\|u_{n}-x_{n}\right\|=0
$$

It also follows from (3.19) that

$$
\begin{aligned}
\left(1-\alpha_{n}\right)\left(1-\gamma_{n}\right)\left\|v_{n}-x_{n}\right\|^{2} & \leq\left\|x_{n}-p\right\|^{2}-\left\|y_{n}-p\right\|^{2} \\
& \leq\left(\left\|x_{n}-p\right\|+\left\|y_{n}-p\right\|\right)\left\|x_{n}-y_{n}\right\| .
\end{aligned}
$$


In view of the restriction (a), we obtain from (3.13) that

$$
\lim _{n \rightarrow \infty}\left\|v_{n}-x_{n}\right\|=0
$$

Since $\left\{x_{n}\right\}$ is bounded, there exists a subsequence $\left\{x_{n_{i}}\right\}$ of $\left\{x_{n}\right\}$ such that $x_{n_{i}} \rightarrow q$. From (3.21) and (3.23), we see that $u_{n_{i}} \rightarrow q$ and $v_{n_{i}} \rightarrow q$, respectively. From (3.21) and the restriction (b), we see that

$$
\lim _{n \rightarrow \infty} \frac{\left\|u_{n}-x_{n}\right\|}{r_{n}}=0
$$

Now, we are in a position to show that $q \in E P\left(F_{1}\right)$. Note that

$$
F_{1}\left(u_{n}, u\right)+\frac{1}{r_{n}}\left\langle u-u_{n}, u_{n}-x_{n}\right\rangle \geq 0, \quad \forall u \in C .
$$

From (A2), we see that

$$
\frac{1}{r_{n}}\left\langle u-u_{n}, u_{n}-x_{n}\right\rangle \geq F_{1}\left(u, u_{n}\right)
$$

Replacing $n$ by $n_{i}$, we arrive at

$$
\left\langle u-u_{n_{i}}, \frac{u_{n_{i}}-x_{n_{i}}}{r_{n_{i}}}\right\rangle \geq F_{1}\left(u, u_{n_{i}}\right) .
$$

In view of (3.24) and (A4), we get that

$$
F_{1}(u, q) \leq 0, \quad \forall u \in C
$$

For any $t$ with $0<t \leq 1$ and $u \in C$, let $u_{t}=t u+(1-t) q$. Since $u \in C$ and $q \in C$, we have $u_{t} \in C$ and hence $F_{1}\left(u_{t}, q\right) \leq 0$. It follows that

$$
0=F_{1}\left(u_{t}, u_{t}\right) \leq t F_{1}\left(u_{t}, u\right)+(1-t) F_{1}\left(u_{t}, q\right) \leq t F_{1}\left(u_{t}, u\right),
$$

which yields that

$$
F_{1}\left(u_{t}, u\right) \geq 0, \quad \forall u \in C
$$

Letting $t \downarrow 0$, we obtain from (A3) that

$$
F_{1}(q, u) \geq 0, \quad \forall u \in C
$$


This means that $q \in E P\left(F_{1}\right)$. In the same way, we can obtain that $q \in E P\left(F_{2}\right)$. Next, we show that $q \in F(S)$. Note that

$$
\left\|z_{n}-x_{n}\right\| \leq \gamma_{n}\left\|u_{n}-x_{n}\right\|+\left(1-\gamma_{n}\right)\left\|v_{n}-x_{n}\right\|
$$

It follows from (3.21) and (3.23) that

$$
\lim _{n \rightarrow \infty}\left\|z_{n}-x_{n}\right\|=0
$$

On the other hand, we have

$$
\begin{aligned}
\left\|x_{n}-S_{n} x_{n}\right\| & \leq\left\|S_{n} x_{n}-S_{n} z_{n}\right\|+\left\|S_{n} z_{n}-x_{n}\right\| \\
& \leq\left\|x_{n}-z_{n}\right\|+\left\|S_{n} z_{n}-x_{n}\right\| .
\end{aligned}
$$

It follows from (3.15) and (3.33) that

$$
\lim _{n \rightarrow \infty}\left\|x_{n}-S_{n} x_{n}\right\|=0
$$

Note that

$$
\begin{aligned}
\left\|S x_{n}-x_{n}\right\| & \leq\left\|S x_{n}-S_{n} x_{n}\right\|+\left\|S_{n} x_{n}-x_{n}\right\| \\
& \leq \beta_{n}\left\|S x_{n}-x_{n}\right\|+\left\|S_{n} x_{n}-x_{n}\right\|,
\end{aligned}
$$

which yields that

$$
\left(1-\beta_{n}\right)\left\|S x_{n}-x_{n}\right\| \leq\left\|S_{n} x_{n}-x_{n}\right\|
$$

This implies from the restriction (a) and (3.35) that

$$
\lim _{n \rightarrow \infty}\left\|S x_{n}-x_{n}\right\|=0
$$

It follows from Lemma 2.2 that $q \in F(S)$. This shows that $q \in \mathcal{F}$. Since $\bar{x}=P_{\mp} x_{1}$, we obtain that

$$
\begin{aligned}
\left\|x_{1}-\bar{x}\right\| & \leq\left\|x_{1}-q\right\| \leq \liminf _{i \rightarrow \infty}\left\|x_{1}-x_{n_{i}}\right\| \\
& \leq \limsup _{i \rightarrow \infty}\left\|x_{1}-x_{n_{i}}\right\| \leq\left\|x_{1}-\bar{x}\right\|
\end{aligned}
$$

which yields that

$$
\lim _{i \rightarrow \infty}\left\|x_{1}-x_{n_{i}}\right\|=\left\|x_{1}-q\right\|=\left\|x_{1}-\bar{x}\right\|
$$


It follows that $\left\{x_{n_{i}}\right\}$ converges strongly to $\bar{x}$. Therefore, we can conclude that the sequence $\left\{x_{n}\right\}$ converges strongly to $\bar{x}=P_{\bar{q}} x_{1}$. This completes the proof.

From Theorem 3.1, we have the following results.

Corollary 3.2. Let $C$ be a nonempty closed convex subset of a real Hilbert space $H$. Let $F$ be a bifunction from $C \times C$ to $\mathbb{R}$ which satisfies (A1)-(A4). Let $S: C \rightarrow H$ be a $\kappa$-strict $p s e u d o c o n t r a c t i o n$. Assume that $\mathcal{F}:=E P(F) \cap F(S) \neq \emptyset$. Let $\left\{\alpha_{n}\right\}$ and $\left\{\beta_{n}\right\}$ be sequences in $[0,1]$. Let $\left\{x_{n}\right\}$ be a sequence generated in the following manner:

$$
\begin{gathered}
x_{1} \in H, \\
C_{1}=H, \\
y_{n}=\alpha_{n} x_{n}+\left(1-\alpha_{n}\right)\left(\beta_{n} u_{n}+\left(1-\beta_{n}\right) S u_{n}\right), \\
C_{n+1}=\left\{w \in C_{n}:\left\|y_{n}-w\right\| \leq\left\|x_{n}-w\right\|\right\}, \\
x_{n+1}=P_{C_{n+1}} x_{1}, \quad n \geq 0,
\end{gathered}
$$

where $u_{n}$ is chosen such that

$$
F\left(u_{n}, u\right)+\frac{1}{r_{n}}\left\langle u-u_{n}, u_{n}-x_{n}\right\rangle \geq 0, \quad \forall u \in C .
$$

Assume that the control sequences $\left\{\alpha_{n}\right\},\left\{\beta_{n}\right\}$, and $\left\{r_{n}\right\}$ satisfy the following restrictions:

(a) $0 \leq \alpha_{n} \leq a<1, \kappa \leq \beta_{n} \leq b<1$;

(b) $0<e \leq r_{n}$

for some $a, b, e \in \mathbb{R}$. Then the sequence $\left\{x_{n}\right\}$ converges strongly to some point $\bar{x}$, where $\bar{x}=P_{\bar{q}} x_{1}$.

Proof. Putting $F_{1} \equiv F_{2} \equiv F$ and $r_{n} \equiv s_{n}$ in Theorem 3.1, we see that $z_{n} \equiv u_{n}$. From the proof of Theorem 3.1, we can conclude the desired conclusion immediately.

Remark 3.3. Corollary 3.2 improves Theorem TT in the following aspects.

(1) From the viewpoint of mappings, the class of nonexpansive mappings is extended to the class of strict pseudocontractions.

(2) From the viewpoint of computation, the set $Q_{n}$ is removed. 
Corollary 3.4. Let $C$ be a nonempty closed convex subset of a real Hilbert space $H$. Let $S: C \rightarrow H$ be a $\mathcal{\kappa}$-strict pseudocontraction with fixed points. Let $\left\{\alpha_{n}\right\}$ and $\left\{\beta_{n}\right\}$ be sequences in $[0,1]$. Let $\left\{x_{n}\right\}$ be a sequence generated in the following manner:

$$
\begin{gathered}
x_{1} \in H, \\
C_{1}=H, \\
y_{n}=\alpha_{n} x_{n}+\left(1-\alpha_{n}\right)\left(\beta_{n} P_{C} x_{n}+\left(1-\beta_{n}\right) S P_{C} x_{n}\right), \\
C_{n+1}=\left\{w \in C_{n}:\left\|y_{n}-w\right\| \leq\left\|x_{n}-w\right\|\right\}, \\
x_{n+1}=P_{C_{n+1}} x_{1}, \quad n \geq 0 .
\end{gathered}
$$

Assume that the control sequences $\left\{\alpha_{n}\right\}$ and $\left\{\beta_{n}\right\}$ satisfy the restrictions $0 \leq \alpha_{n} \leq a<1$ and $\kappa \leq$ $\beta_{n} \leq b<1$ for some $a, b \in \mathbb{R}$. Then the sequence $\left\{x_{n}\right\}$ converges strongly to some point $\bar{x}$, where $\bar{x}=P_{F(S)} x_{1}$.

Proof. Putting $F_{1} \equiv F_{2} \equiv 0$ and $r_{n} \equiv s_{n} \equiv 1$, we can obtain from Theorem 3.1 the desired conclusion easily.

If $S$ is nonexpansive and $\beta_{n} \equiv 0$, then Corollary 3.4 is reduced to the following.

Corollary 3.5. Let $C$ be a nonempty closed convex subset of a real Hilbert space $H$. Let $S: C \rightarrow H$ be a nonexpansive mapping with fixed points. Let $\left\{\alpha_{n}\right\}$ be a sequence in $[0,1]$. Let $\left\{x_{n}\right\}$ be a sequence generated in the following manner:

$$
\begin{gathered}
x_{1} \in H, \\
C_{1}=H, \\
y_{n}=\alpha_{n} x_{n}+\left(1-\alpha_{n}\right) S P_{C} x_{n}, \\
C_{n+1}=\left\{w \in C_{n}:\left\|y_{n}-w\right\| \leq\left\|x_{n}-w\right\|\right\}, \\
x_{n+1}=P_{C_{n+1}} x_{1}, \quad n \geq 0 .
\end{gathered}
$$

Assume that the control sequence $\left\{\alpha_{n}\right\}$ satisfies the restriction $0 \leq \alpha_{n} \leq a<1$ for some $a \in \mathbb{R}$. Then the sequence $\left\{x_{n}\right\}$ converges strongly to some point $\bar{x}$, where $\bar{x}=P_{F(S)} x_{1}$.

Recently, many authors studied the following convex feasibility problem (CFP):

$$
\text { finding an } x \in \bigcap_{m=1}^{N} C_{m}
$$

where $N \geq 1$ is an integer and each $C_{m}$ is a nonempty closed and convex subset of a real Hilbert space $H$. There is a considerable investigation on CFP in the setting of Hilbert spaces which captures applications in various disciplines such as image restoration, computer tomography, and radiation therapy treatment planning.

Next, we consider the case that each $C_{m}$ is the solution set of an equilibrium problem. 
Theorem 3.6. Let $C$ be a nonempty closed convex subset of a real Hilbert space $H$. Let $F_{m}$ be a bifunction from $C \times C$ to $\mathbb{R}$ which satisfies (A1)-(A4) for each $1 \leq m \leq N$. Assume that $\mathcal{F}:=$ $\cap_{m=1}^{N} \operatorname{EP}\left(F_{m}\right) \neq \emptyset$. Let $\left\{\alpha_{n}\right\},\left\{\gamma_{(n, 1)}\right\}, \ldots$, and $\left\{\gamma_{(n, N)}\right\}$ be sequences in $[0,1]$. Let $r_{(n, 1)}, \ldots$, and $r_{(n, N)}$ be sequences in $(0, \infty)$. Let $\left\{x_{n}\right\}$ be a sequence generated in the following manner:

$$
\begin{gathered}
x_{1} \in H, \\
C_{1}=H, \\
F_{m}\left(u_{(n, m)}, u\right)+\frac{1}{r_{(n, m)}}\left\langle u-u_{(n, m)}, u_{(n, m)}-x_{n}\right\rangle \geq 0, \quad \forall u \in C, \\
y_{n}=\alpha_{n} x_{n}+\left(1-\alpha_{n}\right) \sum_{m=1}^{N} \gamma_{(n, m)} u_{(n, m)}, \\
C_{n+1}=\left\{w \in C_{n}:\left\|y_{n}-w\right\| \leq\left\|x_{n}-w\right\|\right\}, \\
x_{n+1}=P_{C_{n+1}} x_{1}, \quad n \geq 0 .
\end{gathered}
$$

Assume that the control sequences satisfy the following restrictions:

(a) $0 \leq \alpha_{n} \leq a<1, \sum_{m=1}^{N} \gamma_{(n, m)}=1,0<c_{m} \leq \gamma_{(n, m)} \leq d_{m}<1$;

(b) $0<e_{m} \leq r_{(n, m)}$,

where $a, c_{1}, \ldots, c_{m}, d_{1}, \ldots, d_{m}, e_{1}, \ldots, e_{m} \in \mathbb{R}$. Then the sequence $\left\{x_{n}\right\}$ generated in the above iterative process converges strongly to some point $\bar{x}$, where $\bar{x}=P_{\mp} x_{1}$.

Proof. Let $S$ be the identity mapping and $\beta_{n} \equiv 0$, then we can obtain from Theorem 3.1 the desired conclusion easily.

\section{Acknowledgment}

This work was supported by Natural Science Foundation of Zhejiang Province (Y6110270).

\section{References}

[1] E. Blum and W. Oettli, "From optimization and variational inequalities to equilibrium problems," The Mathematics Student, vol. 63, no. 1-4, pp. 123-145, 1994.

[2] P. L. Combettes and S. A. Hirstoaga, "Equilibrium programming in Hilbert spaces," Journal of Nonlinear and Convex Analysis, vol. 6, no. 1, pp. 117-136, 2005.

[3] S. Park, "Some equilibrium problems in generalized convex spaces," Acta Mathematica Vietnamica, vol. 26, no. 3, pp. 349-364, 2001.

[4] Q. H. Ansari, S. Schaible, and J.-C. Yao, “The system of generalized vector equilibrium problems with applications," Journal of Global Optimization, vol. 22, no. 1-4, pp. 3-16, 2002.

[5] X. Qin, S.-S. Chang, and Y. J. Cho, "Iterative methods for generalized equilibrium problems and fixed point problems with applications," Nonlinear Analysis: Real World Applications. , vol. 11, no. 4, pp. 2963-2972, 2010.

[6] L.-J. Lin, Z.-T. Yu, Q. H. Ansari, and L.-P. Lai, "Fixed point and maximal element theorems with applications to abstract economies and minimax inequalities," Journal of Mathematical Analysis and Applications, vol. 284, no. 2, pp. 656-671, 2003.

[7] S. Y. Cho and S. M. Kang, "Approximation of common solutions of variational inequalities via strict pseudocontractions," Acta Mathematica Scientia B, vol. 32, no. 4, pp. 1607-1618, 2012. 
[8] S. Y. Cho and S. M. Kang, "Approximation of fixed points of pseudocontraction semigroups based on a viscosity iterative process," Applied Mathematics Letters, vol. 24, no. 2, pp. 224-228, 2011.

[9] T. Kotzer, N. Cohen, and J. Shamir, "Image restoration by a novel method of parallel projection onto constraint sets," Optimization Letters, vol. 20, pp. 1772-1774, 1995.

[10] C. Byrne, "A unified treatment of some iterative algorithms in signal processing and image reconstruction," Inverse Problems, vol. 20, no. 1, pp. 103-120, 2004.

[11] A. N. Iusem and W. Sosa, "Iterative algorithms for equilibrium problems," Optimization, vol. 52, no. 3, pp. 301-316, 2003.

[12] Y. Censor, T. Elfving, N. Kopf, and T. Bortfeld, "The multiple-sets split feasibility problem and its applications for inverse problems," Inverse Problems, vol. 21, no. 6, pp. 2071-2084, 2005.

[13] Y. J. Cho and X. Qin, "Systems of generalized nonlinear variational inequalities and its projection methods," Nonlinear Analysis: Theory, Methods E Applications, vol. 69, no. 12, pp. 4443-4451, 2008.

[14] G. Lopez, V. Martin, and H.-K. Xu, "Perturbation techniques for nonexpansive mappings with applications," Nonlinear Analysis: Real World Applications, vol. 10, no. 4, pp. 2369-2383, 2009.

[15] X. Qin and Y. Su, "Strong convergence theorems for relatively nonexpansive mappings in a Banach space," Nonlinear Analysis: Theory, Methods E Applications, vol. 67, no. 6, pp. 1958-1965, 2007.

[16] S. M. Kang, S. Y. Cho, and Z. Liu, "Convergence of iterative sequences for generalized equilibrium problems involving inverse-strongly monotone mappings," Journal of Inequalities and Applications, vol. 2010, Article ID 827082, 16 pages, 2010.

[17] F. E. Browder and W. V. Petryshyn, "Construction of fixed points of nonlinear mappings in Hilbert space," Journal of Mathematical Analysis and Applications, vol. 20, pp. 197-228, 1967.

[18] H. Zhou, "Convergence theorems of fixed points for $\kappa$-strict pseudo-contractions in Hilbert spaces," Nonlinear Analysis: Theory, Methods E Applications, vol. 69, no. 2, pp. 456-462, 2008.

[19] X. Qin, Y. J. Cho, and S. M. Kang, "Convergence theorems of common elements for equilibrium problems and fixed point problems in Banach spaces," Journal of Computational and Applied Mathematics, vol. 225, no. 1, pp. 20-30, 2009.

[20] X. Qin, S. Y. Cho, and S. M. Kang, "Strong convergence of shrinking projection methods for quasi- $\varphi$ nonexpansive mappings and equilibrium problems," Journal of Computational and Applied Mathematics, vol. 234, no. 3, pp. 750-760, 2010.

[21] J. Ye and J. Huang, "Strong convergence theorems for fixed point problems and generalized equilibrium problems of three relatively quasi-nonexpansive mappings in Banach spaces," Journal of Mathematical and Computational Science, vol. 1, no. 1, pp. 1-18, 2011.

[22] J. K. Kim, S. Y. Cho, and X. Qin, "Some results on generalized equilibrium problems involving strictly pseudocontractive mappings," Acta Mathematica Scientia B, vol. 31, no. 5, pp. 2041-2057, 2011.

[23] A. Tada and W. Takahashi, "Weak and strong convergence theorems for a nonexpansive mapping and an equilibrium problem," Journal of Optimization Theory and Applications, vol. 133, no. 3, pp. 359-370, 2007.

[24] J. K. Kim, "Strong convergence theorems by hybrid projection methods for equilibrium problems and fixed point problems of the asymptotically quasi- $\phi$-nonexpansive mappings," Fixed Point Theory and Applications, vol. 2011, article 10, 2011.

[25] X. Qin, S. Y. Cho, and S. M. Kang, "On hybrid projection methods for asymptotically quasi- $\varphi$ nonexpansive mappings," Applied Mathematics and Computation, vol. 215, no. 11, pp. 3874-3883, 2010.

[26] S. Yang and W. Li, "Iterative solutions of a system of equilibrium problems in Hilbert spaces," Advances in Fixed Point Theory, vol. 1, pp. 15-26, 2011.

[27] A. Moudafi, "Weak convergence theorems for nonexpansive mappings and equilibrium problems," Journal of Nonlinear and Convex Analysis, vol. 9, no. 1, pp. 37-43, 2008.

[28] Y. Haugazeau, Sur les inéquations variationnelles et la minimisation de fonctionnelles convexes [Thése], Université de Paris, Paris, France, 1968.

[29] C. Martinez-Yanes and H.-K. Xu, "Strong convergence of the CQ method for fixed point iteration processes," Nonlinear Analysis: Theory, Methods E Applications, vol. 64, no. 11, pp. 2400-2411, 2006.

[30] W. Takahashi, Y. Takeuchi, and R. Kubota, "Strong convergence theorems by hybrid methods for families of nonexpansive mappings in Hilbert spaces," Journal of Mathematical Analysis and Applications, vol. 341, no. 1, pp. 276-286, 2008. 


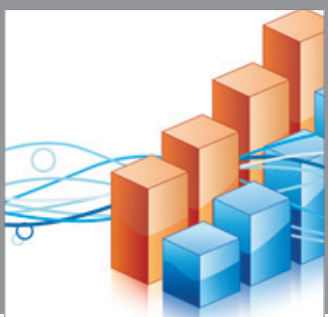

Advances in

Operations Research

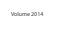

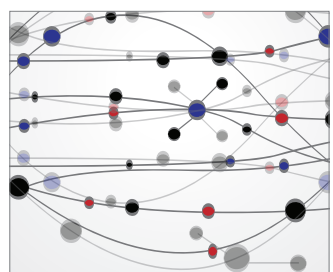

\section{The Scientific} World Journal
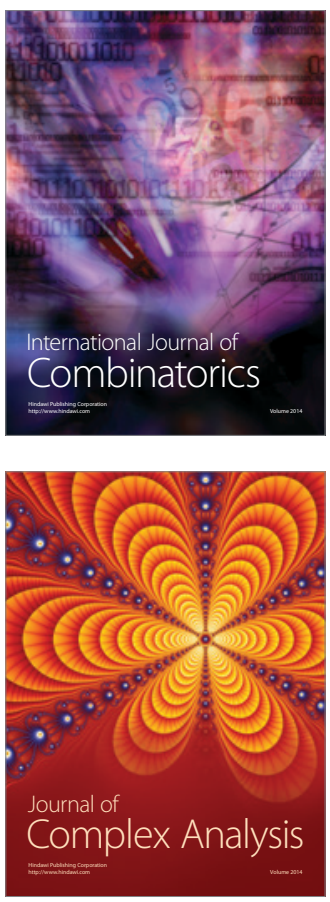

International Journal of

Mathematics and

Mathematical

Sciences
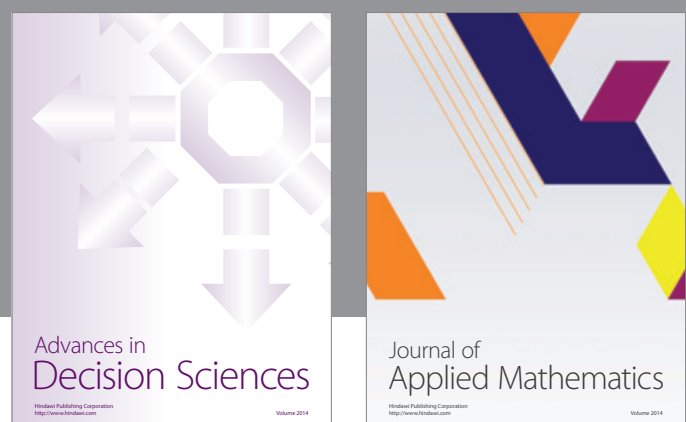

Journal of

Applied Mathematics
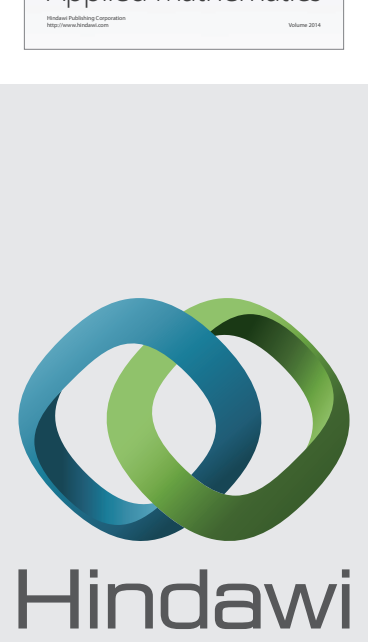

Submit your manuscripts at http://www.hindawi.com
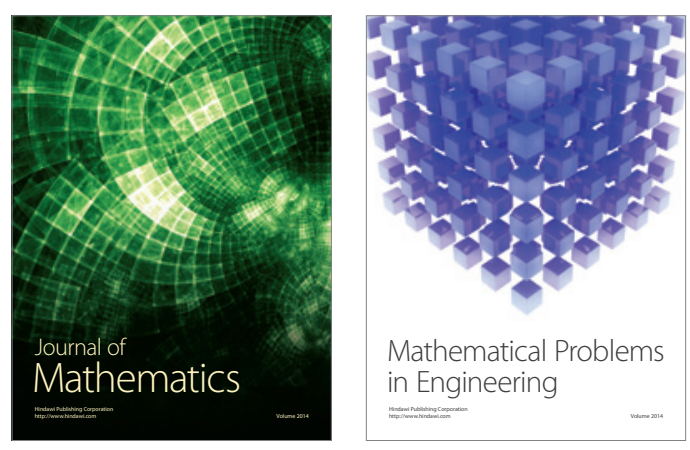

Mathematical Problems in Engineering
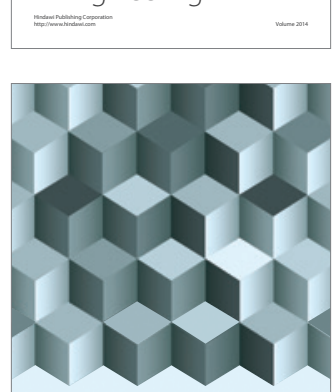

Journal of

Function Spaces
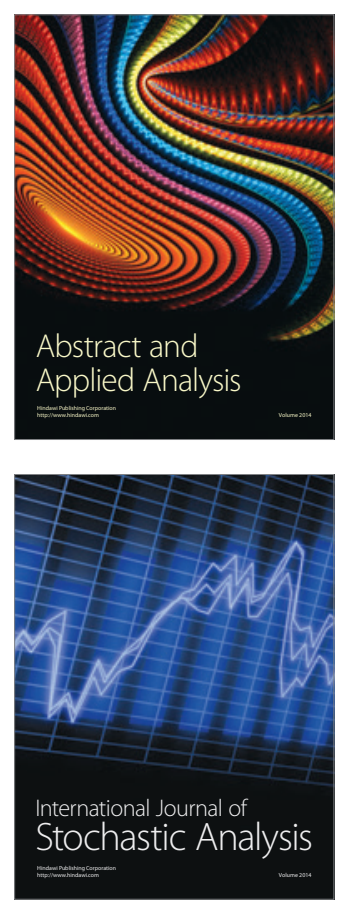

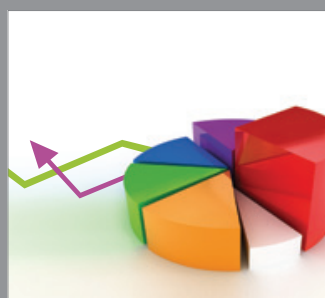

ournal of

Probability and Statistics

Promensencen
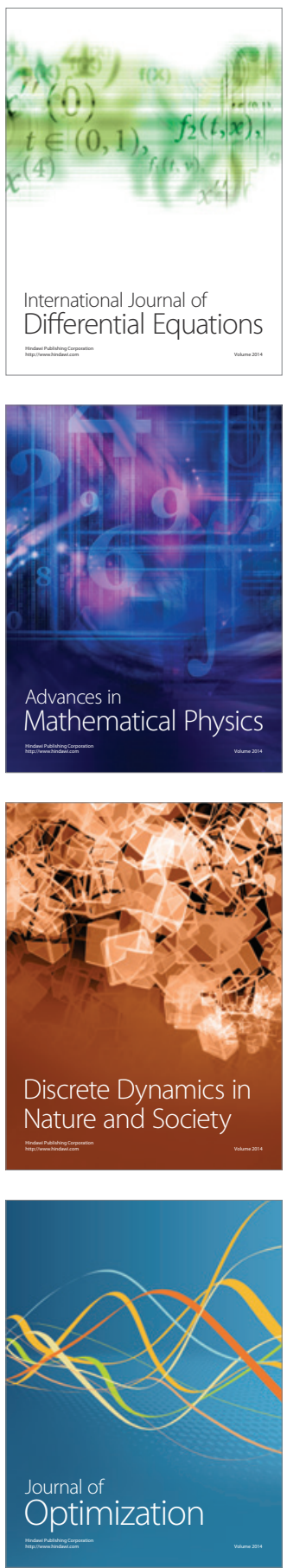